Union - even during 1951 the southern area mines, and opencast mines continued to operate. Strikes that have occurred have generally been confined to one mine and at most the mines within a particular area.

During the course of my ressarch I have become even more convinced that the system for the resolution of conflict evolved in the mining industry could usefully be extended, particularly to industries where present industrial relations are not what they should be. If my hypothesis is correct the Government. Employers Federation. Federation of Labour and the Labour Department could usefully explore the possibilities of implementing like procedures.

\title{
NEGOTIATING WITH THE JAPANESE
}

\author{
ALAN GLOGOSKI
}

\section{INTRODUCTION}

Many characteristics of Japanese society and institutions are absolutely unique. These must be recognized and understood if an effective dialogue with the Japanese is to be achieved.

Traditional Japanese values are not derived from or even influenced to any significant degree by Judeo-Christian traditions or beliefs. Many things that are taken for granted in the West are therefore completely alien to their culture and are outside their traditional system.

I would like to touch on some important aspects of the traditional Japanese culture, society, national character and political system, and how these influence their negotiating habits.

\section{COMMUNAL}

In nearly all activities and issues the Japanese traditionally think of themselves as members of a group, and their satisfactions are largely expected to come through group fulfillment of group objectives. In traditional Japanese culture and to an amazing degree today one of the worst sins is to display an egoistic disregard of dis. interest in, or resistance to group mores attitudes, taboos, traditions or objectivesor often just to display any individualism at all

Japan is probably the only large country in the world in which everybody concerned - management. labour. consumers, family. the general public - tends to identify the success of a business firm with the success of the nation and with his own individual success. The firm's triumph is the nation's triumph and also his own triumph This shows up in foreign trade where the Japanese co-operate to a remarkable degree even while competing. Whilst the Japanese exporter tries best for his own firm he takes almost as much pleasure in any Japanese export success.

Robert Huntingdon' comments "that the Japanese personality has weak, indistinct. permeable boundaries between the self and other, is dependent rather than independent, group co-operative rather than self reliant, conforming rather than innovative and accepting of personal rather than rational legal authority."

Ideal types of character are an important indication of a nation's culture. Probably to a degree unmatched in any other culture the Japanese have exalted such qualities as loyalty, faithfulness, devotion. dedication etc, as associated with the faithful servitor on the one hand - and the corresponding qualities of loyalty, protection, meticulous regard for ritual, codes. obligations etc. appropriate to the responsible. paternalistic Confucian master on the

\footnotetext{
- ALAN GLOGOSKI is Assisiant Manager, Mitsubishi New Zealand Ltd His article was the basis for a talk given in October 1977 to an Action Learning Systems' workshop on Developing Negotiation Skills

F-Huntingdon. Robert, 'Comparison of Western and Japantese Cultures: Monumenta Nipponica. Tokyo. Vol. XX111. No $3 \cdot 4$ D. 477 .
} 
other. This is presumably one of the reasons a Japanese factory works so well: It is also of course a major source of the unsurpassed ability of the Japanese at purposive, communal action.

\section{NATIONALLY EGOISTIC AND HIERARCHICAL}

The Japanese people have almost always had a very clear conception of themselves as being special, as being Japanese and therefore unique.

According to Ruth Benedict2 "The Japanese character is in large measure the product of explicit training in the need for self sacrificing pursuit of duty - of duty towards the nation, the company, the family status, superiors and personal benefactors, and of the duty to maintain ones good name in order to retain the esteem of ones group - a preoccupation which has made shame rather than guilt the major moral sanction."

The Japanese also have very little concept of equality. Traditionally every Japanese is part of a hierarchical structure. There are people who rank above every individual except the Emperor and, except for the youngest daughter of a member of the outcast burakus, there are people beneath. To say in Japan that certain people are equal generally implies that they are an equal distance from some common superior.

The Japanese do not think of themselves as being racist. However in some ways Japan is the most racist nation in the world. The Japanese in comparison with most other groups are relatively pure racially. There are, so to speak, no blond, red haired or blue eyed Japanese and the attitude of the Japanese towards mixed marriage is very different to that of say the Chinese or French. If somebody is born of a mixed marriage in China or France but grows up perfectly familiar with and skilled in the indigenous culture he is largely accepted. That is not true in Japan. The children of mixed marriages are more or less permanently barred from participating fully and comfortably in society. Those bars also hold against children born in Japan but of Korean or Chinese parentage.

An important consequence of this is that the Japanese are unwilling to import inex- pensive labour into their country. It also implies that when they go to other countries to exploit the inexpensive labour there they do it with very little intermarriage and perhaps without easy social intercourse.

\section{EMPHASIS OF THE SPIRITUAL AND APPARENT OVER THE MATERIAL AND REAL}

This aspect takes a number of different forms. In looking at the duality of the politics of Japan, for example, one notices thiti there have generally been people whom we would call "front men," their behaviour is honourable and exemplary, and it is always in accord with valued principles and traditions: it is to them that respect and loyalty are due. Then there are others behind the scenes who manipulate the system and are often very practical and pragmatic; but they are considered unworthy even of discussion. Indeed in many cases the Japanese seem to wish to take the apparent as more important than the real. At least as far as discussion of issues is concerned, the Japanese often demonstrate an unwillingness to come to grips with simple facts, preferring instead a discussion of the higher moral issues - sometimes in a way that a Westerner would judge to be an outright denial of reality.

The Japanese, who are endowed with a highly developed aesthetic sense, tend to be better at feeling things than analysing them. This makes them remarkably casual about written documents. Where we in cases of dispute tend to say "Let us return to the original document or contract and see what it said," many Japanese would not think the matter of sufficient importance to be mentioned. For most Japanese the critical issue is the present and past emotional background of a relationship. the personal issues and attributes that led to its creation and the current power or bargaining situation.

The Japanese would want to know: what was the ambience of the situation in which the document was signed; what events have occurred since the signing and what are the current relationships of the concerned parties? - all things are are usually irrelevant to a European involved in a dispute over a contractual issue. A very good textbook on Japan, for example, described this characteristic Japanese attitude as follows:

2-Benedict Ruth, The Chrysanthemum and the Sword, Cleveland, Ohio: Meridian Books, 1967 (copyright
1946). 
Japanese businessmen avoid precedent and deprecate legal, contractual obligations because they believe an agreement valid only so long as the conditions under which it was reached continue to hold true. They view contracts with suspicion and draw them up with an eye to flexibility, in contrast to the American practice of trying to close every conceivable loophole. Few disputes between Japanese businesses ever go to court because this would be an admission that they have not been able to negotiate a compromise. Courts operate on the same theory and endeavour to mediate a compromise if a dispute comes to them in desperation. Courts are deliberately slow, not only because care is required but because the longer a court holds off, the better the chance the two parties will be forced to compromise.

A Westerner entering into a contract with a Japanese individual or firm will find that a contract is often considered an agreement to enter into a general course of conduct rather than something fixing the precise terms of performance. As a result, there may be basic disagreement over whether or not the agreement has been breached 3

Much the same approach mentioned here with regard to business relationships also holds for treaties and other international agreements and understandings. If there is a change in power or other relationships but new emotional relationships have not been built up, then no treaty is likely to have serious moral binding effect on the Japanese.

It should be noted however that there now seems to be a decided trend among younger Japanese intellectuals to be pragmatic, matter of fact, detached and coolin contrast to the traditional pattern which can only be categorized as dogmatic, moralistic, ideological and more interested in appearance than in reality and actuality.

\section{THE POLITICS AND TECHNIQUES OF GROUP CENTERED DECISION MAKING}

The Japanese employ a diffuse groupcentred decision making apparatus. In this process the views of all parties who have an interest in the decision are canvassed and an attempt is made to accommodate each of these views. Direct confronlations are avoided whenever possible, and many institutional mechanisms. including the use of middlemen, are employed to prevent them. A dissident party may also be placated by granting him a concession on some issue totally unrelated to the decision at hand - or by conceding an obligation to make up, whenever the opportunity occurs, any losses suffered by a generous concession on the matter at issue.

The Japanese system is reciprocal, Everybody who has been generous in concession or who has done something out of the ordinary to facilitate consensus is remembered, and to a remarkable degree he is eventually repaid. This is true if it is a matter of a favour a corporation has done for the Government or a favour an individual has done for a corporation.

In most cases the decision-making process is less simple than I have indicated. Being so diffuse, it is difficult to isolate the source of the initiative behind an idea; an initiative can come from almost anyone and often originates quite low in organizations. A similar difficulty exists in determining who is the effective decision-maker, since the decision is in a sense made by all the interested parties each of whom has veto power. Frequently the man with the senior position in an organization is not necessarily the one who wields effective power or possesses the ability to satisfy
dissidents.

And though the Government has a voice in almost all major business decisions and may itself assemble the views of various interested parties, it by no means exercises final decision-making power. Even when the Government is involved and has nominal authority, an effort must be made to accommodate each viewpoint - including those of interested private parties.

A virtue of the Japanese system is that the effort to keep all parties satisfied practically eliminates the demoralizing "squeaky-wheel" phenomenon. But if some party or group remains - despite all discussions and compromise - oppos.
ed to a given initiative, the result is usually

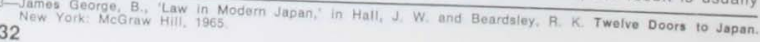


a non-decision - i.e. a decision to stall and keep the question circulating indefinitely until the matter is either dropped or a change in conditions permits unanimous agreement.

In some cases one group may ram through a decision against the wishes of a weaker opposition group; the Japanese characterize the resulting state as a "tyranny of the majority." Thus to the Japanese action based on a ten to two vote does not represent a 'group decision'; it reflects instead the domination of a tyrranical majority over the firmly held desires of the minority. The proper outcome should be some form of temporizing 'non-decision.

One result of this technique is a thorough discussion of the issues by all who are affected and an equally thorough educational process. All involved parties receive and contribute to this discussion of the options, facts, and philosophy behind a decision before that decision is finally made. Each party carefully prepares arguments backing its position and this information is circulated. Thus once an accommodation is reached, the staff work has been completed and each party is aware of its role in executing the decision. Typically the Japanese are prepared to move very quickly once an issue is resolved.

One of the most interesting bureaucratic manifestations of the politics of consensus and the way it can be used or applied is through the institution of what is called "Ringi."

As this is applied in Government bureaucracies and large private bureaucracies, junior people in a department achieve a consensus among themselves on an issue on which they think a decision should be made, and then they draft a paper on it. The department head will approve the paper. This paper will then be circulated in other departments, usually at the lower levels, with much discussion and correction ensuing. The paper may go back and forth a number of times as changes are made, and eventually a reasonable consensus is achieved at the lower levels. The paper is then passed to the department heads and from there to the corporate heads, who now are under rather serious pressure to sign it and forward it to the minister/presidents office for final implementation.

Thus Ringi is simply a special institu- tional arrangement for obtaining the kind of consensus we have just described, but one in which most of the initiative comes from the bottom or, middle levels.

The other main method of achieving agreement is called 'matomari' which can be part of the 'Ringi' process or independent of it. The process is as follows:

A typical decision-making meeting opens with a statement of the problem by the group's senior member. Each member then exposes a slight portion of his thinking, never coming out with a full-blown, thoroughly persuasive presentation. After this, he sits back to listen to the same sort of exposition from the others. The Japanese, who has a tremendously sensitive ego, does not wish to put himself in a position where he is holding a minority or, worse, an isolated view. Nor does he wish to risk offending an associate by coming out bluntly with a proposal that might run contrary to his colleague's thoughts. The discussion goes on at great length, each person slowly and carefully presenting his opinion, gradually sensing out the feelings of other people, making a pitch subtly following it without pressing if he finds it acceptable, quietly backing off and adjusting his views to those of the others if he finds himself not in tune with the evolving consensus. When the leader of the group believes that all are in basic agreement with a minimally acceptable decision, he sums up the thinking of the group, asks whether all are agreed, and looks around to receive their consenting nods. Nothing is crammed down anyone's throat. If, by chance, a consensus does not emerge and a deadlock seems likely, the group leader does not press for a decision, does not ask for a vote, does not rule that no consensus seems possible and thus embarrass people. Instead, he suggests that perhaps more time is needed to think about the problem, and sets a date for another meeting. The people involved can then meet informally to adjust views or. if there are positions that are apart, mediators will go back and forth between the people holding the opposing positions and attempt to narrow down the differences. By the time the next meeting is called, the differences most likely will have been straightened out and the pro- 
cess can be moved forward to a final decision. In all of this, the most important principle is not to stand on principle but to reach agreement. All else is subordinate to this point.4

\section{AFFECTING JAPANESE DECISION MAKING FROM THE OUTSIDE}

It must be realized that this process of 'group centred decision making' is a relatively autonomous one, at least as far as outsiders are concerned, and can more easily be affected negatively than positively. That is, any pressures to accelerate it or make it reach an immediate decision are likely to be regarded with intense hostility and suspicion.

But that is not to say that foreigners have not been able to influence decisions. If an outsider can anticipate the eventual form of the consensus to emerge and can articulate it at the appropriate moment, he may perform a valuable service to the Japanese discussion. And sometimes an outsider has an advantageous perspective for attempting to do exactly that. It is however particularly important that such an outside solution be advanced in time to influence the discussion and before the chief negotiator - or an important group - has adopted positions that are more or less contrary to the outsiders proposed consensus.

In any case it is clear that the outsider could go to some pains to provide the Japanese discussants with relevant inform ation and to explain the reasons for his own preferences. He should not wait until the consensus has been largely achieved before joining the discussion, nor should he expect immediate results. (He cannot possibly convince the individuals he is talking to, as they represent a larger communal constituency, which must be consulted). Therefore to the extent that the outsider has relevant and important information, ideas, concepts, arguments, etc., he should attempt to get them in as early as possible.

For many issues on which such decisions are being made, there are out-groups not directly consulted, at least in the particular 'game.' In the political arena these might include newspapers, intellectuals, students, workers, radicals, the opposition political parties, and so on. In any parti- cular context there will be some such outgroups of varying degrees of importance. They can sometimes influence both the content and timing of the decision by threatening to precipitate a confrontation before the accommodation process has had sufficient time to work. In particular, they can exert enormous delaying influence, since it is extremely difficult, if not impossible, for even a pronounced majority to ram through legislative or adminstrative decisions against the will of a determined minority, for, as indicated earlier, to do so would be thought of by most Japanese as a "tyrranny of the majority:

It follows therefore, that an outside business firm, government bureau, or other organization should not normally try to rush the decision process, because to do so will often only result in the erection of barriers and animosity. Instead one should find out where the staff work on a problem is being done, provide the staff with relevant information, and present opinions mostly when the Japanese ask for them. Since the Japanese do intensive staff work to educate themselves, any effort to rush or channel this process is likely to raise suspicions of deception. Unsolicited opinions should be presented only as the process goes on. In particular one should not take a rigid position: otherwise the Japanese might become frustrated and give up any hope of accommodation. Also one might take a lesson from the Japanese and occasionally propose side deals or suggest other means of accommodation to make it easier for the Japanese to move appreciably in the desired direction. And since decisions are reached only after an extended period of discussion among the large number of interested Japanese parties who often hold widely divergent views, anyone anticipating the eventual agreement and articulating it at the right moment may not only facilitate but sometimes influence the
decision.

The particular characteristics of Japanese society and institutions discussed here are by no means presented as curiosities or minor items of information. They are important to an understanding of the mechanisms by which a decision will be made. or avoided, and the conditions under which it will be implemented. A Westerner

Aatioran, Aichard, Japan: Images and Realities, Now York- Alfred A. Knopf, 1969, pp. 92.93. 
attempting to shortcut an understanding of or a sensitivity to these special characteristics is likely to be in for a rude shock in his dealings with the Japanese. Attempts at salesmanship with the finest and most persuasive of Western presentations are quite likely to fail. Negotiations in any area can become impossible. Yet generally the Westerner will have done his best, will have received a warm reception, and will have no idea why his plans have made no progress. 